\title{
Entre a guerra, a natureza e a infância - um retrato das marcas pós-coloniais na obra A guerra dos fazedores de chuva com os caçadores de nuvens: guerra para crianças, de Luandino Vieira.
}

\author{
Between war, nature and childhood - a portrait \\ of postcolonial scars in the work A Guerra dos \\ fazedores de chuva com os caçadores de nuvens: \\ guerra para crianças, by Luandino Vieira
}

\author{
José Luís Pires Laranjeira * \\ Júlia Parreira Zuza Andrade *
}

\begin{abstract}
Resumo: $O$ artigo analisa a obra $A$ guerra dos fazedores de chuva com os caçadores de nuvens destinada para o público infantojuvenil do angolano Luandino Vieira. Através de uma perspectiva pós-colonial, é descortinada a violência sofrida por Angola em sua colonização, culminando na luta de independência. A natureza participa ativamente dos acontecimentos, numa metáfora com a nação que passa a ser repensada e as crianças ocupam papel de destaque, sobretudo ao final da batalha. A partir do estudo, é possível reavaliar os vestígios coloniais e pós-coloniais contidos na obra, ampliando a discussão sobre os pós-colonialismos nas literaturas africanas de língua portuguesa.
\end{abstract}

Palavras-chave: Literatura angolana, pós-colonialismo, Luandino Vieira, literatura infantojuvenil, guerra de independência.

Abstract: This article analyzes Luandino Vieira's children and youth book $A$ guerra dos fazedores de chuva com os caçadores de nuvens. With a postcolonial approach it unveils the violence imposed to Angola through its colonization and with its high point with the war of independence. Nature has an active role in the outcomes of the narrative as a metaphor to the process of rethinking the nation. In addition, the children have also a major role, especially on the final battle. With this study it is possible to reevaluate the colonial and postcolonial residues contained in the literary work. Thus, it will broaden the discussion of Postcolonialisms in African literature in Portuguese.

Keywords: Angolan literature, postcolonialism, Luandino Vieira, children and youth

\footnotetext{
* Professor da Universidade de Coimbra (FLUC).

${ }^{* *}$ Doutoranda da Universidade de Coimbra (FLUC).
} 
literature, war of independence.

\section{ntrodução}

Aqui se analisa a obra infantojuvenil A guerra dos fazedores de chuva com os caçadores de nuvens: guerra para crianças, escrita pelo angolano Luandino Vieira. O autor conta com outras obras para crianças e jovens, como Kaputu Kinjila e o Sócio dele Kambaxi Kiaxi (2010) e Kaxinjenguele e o poder: uma fábula angolana (2012) e possui a infância como um tema recorrente em suas narrativas voltadas para público adulto, como se nota, por exemplo, nas suas primeiras obras publicadas, A cidade e a infância, Vidas novas ou Luuanda.

O livro em questão narra a luta travada entre os fazedores de chuva, representados pelos angolanos colonizados e os caçadores de nuvens, representados pelos colonizadores. A história é contada com tópicos centrais, descrevendo, quadro a quadro, a batalha que evidencia importantes assuntos, como o antagonismo de força entre os oponentes, a guerra da linguagem que denuncia a opressão sofrida pelos colonizados, a revisitação de narrativas orais tradicionais de Angola e o comportamento não usual das crianças diante desse cenário, capaz de questionar os desdobramentos e marcas da luta.

Um dos pontos de destaque na obra é a natureza, sobretudo a água. Utilizada em diversos estados e múltiplos sentidos, serve de simbologia para a guerra de independência angolana até ao seu desfecho, culminando com a morte de um antigo rio e as devidas consequências, em que os conceitos de nação, identidade e pertencimento são repensados. A palavra aparece inclusive no título, sob a forma de chuva. Dessa maneira, torna-se pertinente analisar a ocorrência da água e seus vários desdobramentos conotativos: "A água concentra em seu simbolismo uma gama de significados, sendo alguns bastante conhecidos. Célebre alegoria do tempo, a imagem da água traz ainda significações de matéria-prima, de elemento iniciático e capaz de conduzir à regeneração" (Alves, 2012: 83). A sua representação pode ser cruzada com os ideais de nação e identidade presentes no livro, além do renascimentos e ritos de passagem.

Como metáfora da nação, o rio/água apresenta vários elementos que enriquecem a discussão sobre a identidade e o pós-colonialismo, aspectos qua- 
se imprescindíveis ao se estudar obras africanas. São traços constitutivos da sua natureza e que se entrelaçam nos textos de Luandino Vieira, apresentados de diferentes formas.

\section{Da água à rocha: a natureza como reflexo de uma nação}

Em A guerra dos fazedores de chuva com os caçadores de nuvens, a ideia de água como metáfora da nação/identidade é notada no início da obra:

4. Todas as noites Mbumba iá Kibaia, o Kibaia Kinene, fazia bater todos os tambores e chamava a chuva; e a chuva chovia da lua; e a pólvora não disparava;

5. E todos os dias Lengalengenu mandava disparar todas as espingardas; e as nuvens fugiam;

6. Então o sol secava o fim da chuva; mas vinha a noite e a chuva chovia (Vieira, 2006: 7).

A guerra, como indica o nome da obra, é travada em função da água, pois enquanto o quilombo de Kibaia Kinene, representando os angolanos, chamava a chuva, o exército de Lengalengenu, representando os portugueses, espantava as nuvens e não deixava que chovesse. $\mathrm{O}$ sol e a noite conseguiram estabelecer, por certo período, o equilíbrio entre as duas forças, mas era inevitável o choque entre elas. Os posicionamentos são antagônicos; enquanto o Grande Kibaia tocava os tambores, Lengalengenu usava a força das armas. $\mathrm{O}$ primeiro gesto pode significar a manutenção dos costumes mais antigos angolanos, ao passo que o segundo demonstra a violência portuguesa empregada para alcançar os seus objetivos de dominação. Para intensificar a diferenciação, o ritual do angolano é noturno, ao passo que o português dispara as espingardas de dia. Entre os dois lados da disputa, acha-se a terra, a nação angolana. A analogia da terra como nação é, segundo Fonseca (2008), amplamente utilizada nas cinco literaturas africanas, em que a afirmação da terra, costumes e mitos marca a sua singular diferença no conspecto de todas as literaturas de língua portuguesa. Existe uma correlação quase direta entre a guerra tratada na história com a guerra de independência de Angola, em que é utilizada a água como simbologia das diferenças entre colonizados e colonizadores. Vale recordar que, no livro emblemático 
Luuanda (1963) de Luandino Vieira, também a chuva e, em geral, a água, já marcavam uma posição simbólica na economia do sentido do livro.

É a violência de Lengalengenu, percebido como um agente externo, que interfere no ritmo da natureza e altera a ocorrência das chuvas: "1. Sucedeu então que Lengalengenu gastou toda sua pólvora; e a lua não tinha mais água para chover; 2. Veio o cacimbo" (Vieira, 2006: 12). O desequilíbrio causado pelo encontro dos fazedores de chuva com os caçadores de nuvens fica evidente, pois Lengalengenu foi o causador do cacimbo, a estação da seca em Angola. Parece sintomático que a consequência dos atos do português provoque o cacimbo. 0 primeiro sentido da palavra seca remete à escassez de água, elemento vital para a sobrevivência humana, sobretudo onde ela não é abundante. Em um sentido mais amplo, a seca pode ser entendida como escassez de vida, de esperança, em que a aridez ultrapassa o solo e atinge o cotidiano dos seres humanos. $\mathrm{O}$ cacimbo que o povo angolano se viu forçado a passar ganha conotação do grande desequilíbrio natural, social e cultural que o processo colonizador causou. Intensificando a crítica sobre a opressão sofrida pelos países africanos colonizados, Césaire (1978) afirma que a colonização se iguala à coisificação e que a colonização é a "testa de ponte numa civilização da barbárie donde, pode, em qualquer momento, desembocar a negação pura e simples da civilização" (Césaire, 1978: 21). A negação da civilização comentada pelo intelectual pode ser notada primeiramente na obra de Luandino Vieira, com a seca advinda da caça às nuvens feita pelos portugueses, subtraindo a água dos angolanos.

Como se pode perceber no trecho acima citado, retirado da obra de Luandino Vieira, além da chuva, outros elementos da natureza estão em foco: o sol, o rio, a lua, a seca. Dentre esses, a leitura será mais atenta ao sol e à lua. O sol era o elemento relacionado com os portugueses: " 5 . E todos os dias Lengalengenu mandava disparar todas as espingardas; e as nuvens fugiam; 6 . Então o sol secava o fim da chuva" (Vieira, 2006: 7). De acordo com Chevalier e Gheerbrant (2005), o sol está disposto no centro do céu, o que pode ser lido como no centro do universo, uma vez que os planetas orbitam à sua volta. E carrega uma alta carga destruidora, pois é o princípio da seca. Ao se ler essas simbologias no livro, é possível entender os portugueses como causadores de destruição do quimbundo, o que pode estar relacionado com certa arrogância, ao se perceberem como mais importantes do que os colonizados. Os angolanos são representados pela lua: "4. Todas as noites Mbumba iá Kibaia, o Kibaia Kinene, fazia bater todos 
os tambores e chamava a chuva; e a chuva chovia da lua; e a pólvora não disparava" (Vieira, 2006: 7). Referindo novamente Chevalier e Gheerbrant (2005), a lua simboliza o ritmo biológico, como o ciclo da natureza, sendo conhecida também como o símbolo da fertilidade. As posições contrárias entre os dois povos ficam mais claras, pois enquanto os portugueses eram representados pelo sol e pela destruição, os angolanos possuíam como símbolo a lua, marco da renovação e da fecundidade. Todos os símbolos presentes na trama podem ser vistos como a força da terra na narrativa, em que toda a natureza é participante ativa dos acontecimentos, criando com os humanos uma relação reativa, como se fosse um espelho, refletindo os rumos que a guerra da independência tomou. Os símbolos metaforizariam a nação, pois garantem a ideia de pertencimento dos personagens à terra, através da comunhão entre natureza e seres humanos. E, por serem cultuados pela tradição, os elementos citados reforçariam, dessa maneira, os laços com a ancestralidade, criando um diálogo constante entre passado e presente.

A ligação da natureza com os acontecimentos da história pode também ser vista nos últimos trechos de $A$ guerra dos fazedores de chuva com os caçadores de nuvens, em que lama, pedra e rocha de ferro representam a ideia de nação e identidade: "10. Mbumba iá Kibaia nunca mais fez chover; o sangue da guerra virou lama; e a lama virou pedra; e a pedra, rocha de ferro" (Vieira, 2006: 20). Após a vitória dos fazedores de chuva contra os caçadores de nuvens, não era mais necessário tocar os tambores para invocar a chuva. A natureza e a vida dos habitantes do quilombo de Kibaia Kinene retornam à ordem, à normalidade e os fenômenos naturais voltam a acontecer. São mostradas etapas do processo do pós-guerra no livro, metaforizadas no sangue que vira lama, lama que vira pedra e pedra que vira rocha de fogo. A primeira passagem, sangue da guerra que vira lama, pode ser entendida como o grande número de mortos, o grande derramamento de sangue causado pela guerra. Mas, como demonstra Fanon (1968), a luta era necessária: "pensamos que a luta organizada e consciente empreendida por um povo colonizado para restabelecer a soberania da nação constitui a manifestação mais plenamente cultural que se possa imaginar" (Fanon, 1968: 205). Dessa forma, a palavra lama não foi escolhida de maneira aleatória. Um dos empregos do termo registrado no século XIX por Cunha (1986) é ser a mistura de água e barro utilizada para limpeza de nódoas. Ao levar a interpretação para o cerne do livro, o sangue que foi derramado na guerra simbolizaria a nova fase 
que seria iniciada a partir daquele momento, pois a batalha era necessária para limpar as nódoas do passado colonial e principalmente o sangue dos mortos na batalha, mas sem esquecê-los ou deixar de questioná-los. A lama seria usada para limpar o país e permitir que surgisse um tempo de reflexões e análises. Em outra perspectiva, a lama representa, segundo Chevalier e Gheerbrant (2005), a matéria primordial da qual o ser humano foi retirado. Isso poderia remeter à ideia de que todos os humanos são feitos da mesma essência, sendo iguais sob esse ponto de vista, o que deveria impedir a desigualdade e a guerra entre eles. Outra ideia suscitada seria a de relacionar essa lama inicial ao ser angolano, simbolicamente (re)nascido após a guerra e que se torna responsável por dar início à evolução e à transformação de sua terra e de seu povo.

Dando sequência ao processo de transformação comentado, a lama se torna pedra. A pedra é um dos elementos mais ricos em significações e simbologias da natureza. Segundo Chevalier e Gheerbrant (2005), dentre seus inúmeros significados, pode simbolizar a Terra-mãe para os gregos e a pedra fundamental para a construção de um novo ser humano, conforme a Bíblia. A partir dessa pedra surgida da lama, a nova sociedade angolana seria construída, em que o ser humano advindo dessa transformação seria o agente que mudaria o rumo da história e da nação. Ainda segundo os escritos bíblicos, a pedra simboliza a sabedoria, o que poderia indicar um olhar mais arguto e consciente do angolano após a guerra colonial. E, para finalizar, a terceira etapa seria da pedra transformada em rocha de fogo. A evolução da nação angolana se mantém, já que, depois de inaugurado um tempo inicial e um "homem novo" (segundo a ideologia e a terminologia revolucionária da época), a pedra, antes bruta, torna-se rocha de fogo. Aquela pedra não é somente pedra; ela guarda em si a força e a capacidade de regeneração. Para Bachelard (2008), o fogo é a simbologia maior da pureza, transmitindo valores misteriosos, indefinidos e surpreendentes, além de sugerir o desejo de mudança, de apressar o tempo. É também utilizado para limpar o solo antes do plantio, purificando-o. Tal como a terra se prepara com o fogo para ser semeada, assim a nação angolana estaria pronta para receber o novo angolano, que carrega o fogo da mudança. Vale lembrar que o fogo é um dos elementos presentes nos ritos religiosos antigos, o que poderia conectar Angola com seu passado tradicional.

A relação intrínseca do meio ambiente com os personagens transmite o caráter identitário do livro: "3. Os crocodilos disseram: makalanga, somos os com- 
pridos de navegar o rio; 4. Os jacarés disseram: matatu ma'xi, somos da terra e da água parada" (Vieira, 2006: 10). Ao se apresentarem como "compridos de navegar o rio" e "da terra e da água parada", os crocodilos e os jacarés, respectivamente, assumem-se como pertencentes àquele local. Ao invés de relatarem atos de bravura ou outras características pessoais, os animais, ao se descreverem, enfatizam a relação que teciam com a natureza, percebendo-se como parte integrante da comunidade. Nessa passagem, mais do que perceber a influência do missosso angolano tradicional no ato de falar dos animais, nota-se que os elementos da terra adquirem cunho identitário para os bichos:

Essa dinamização identitária, que se manifesta no diálogo da Terra e com os elementos naturais (vegetais, animais, cósmicos e cosmológicos), opera uma espiritualização da Natureza, resultando-se a sua simbolização, e, assim, a sua instituição como lugar político, origem da ideia de nação. (Mata, 2001: 91)

Fica ressaltado que o ato de se mencionar a natureza na obra cria uma noção de identidade coletiva, em que todos os indivíduos possuem traços em comum para compartilharem, como o leito do rio ou a lua. Enfatizar esses elementos poderia germinar a noção de pertencimento, que se faz necessária ao se refletir sobre uma nação recente. Um paralelo com a necessidade de reconhecimento de origem pode ser traçado, pois assim como os animais afirmavam ser daquela terra, os angolanos também deveriam agir de maneira semelhante, ratificando a ideia de nação que defende Inocência Mata (2001). Nota-se, em A guerra dos fazedores de chuva, o debate do sentimento de angolanidade, metaforizado em animais e em outros elementos da natureza.

É importante notar que, no excerto de A guerra dos fazedores de chuva com os caçadores de nuvens selecionado para a análise, cada animal se reconhece de maneira distinta, única. Os crocodilos eram os compridos de navegar o rio e os jacarés da água quieta, diferentes entre si. A analogia com a construção identitária individual também se faz na obra, pois, mesmo tendo a ideia de nação como denominador comum, não se pode ignorar a identidade de cada africano, no caso, dos angolanos: "Não importa o que os africanos compartilhem, não temos uma cultura tradicional comum, línguas comuns ou um vocabulário religioso e conceitual comum" (Appiah, 1997, p. 50). A fala do estudioso reitera a individualidade apresentada na obra de Luandino Vieira, evitando o prisma obtuso e 
generalizador por que, muitas vezes, a África é vista, entendida como detentora de núcleo rigidamente estruturado e capaz de irradiar as mesmas características por todo o continente.

\title{
Pós-colonialismo, identidade, nacionalismo: o repensar de uma história
}

Na passagem "6. E disse Kibaia, o Grande: Sai da minha terra! 7. E Lengalengenu não quis sair; bateu a espingarda, disse: A terra é do Muene-Putu" (Vieira, 2006: 13), o Grande Kibaia tenta expulsar de forma categórica Lengalengenu de sua terra e o que se destaca no diálogo é o reconhecimento da terra por parte do angolano, consciente de que aquele território lhe pertence por direito e que os portugueses precisavam ir embora. Nota-se aqui uma intertextualidade de Luandino Vieira com o poema 'Havemos de voltar', de Agostinho Neto (1987) e escrito em 1960, que reafirma o local que os angolanos precisam de reaver. Todo o poema percorre as riquezas naturais e tradições que haviam sido parcialmente retiradas de Angola em função da colonização, e termina profeticamente:

\begin{abstract}
À bela pátria angolana nossa terra, nossa mãe havemos de voltar
\end{abstract}

Havemos de voltar À Angola libertada Angola independente (Neto, 1987: 148).

Tanto o poema de Neto (1987) como a obra de Luandino Vieira indicam a busca por Angola, pela terra-pátria que havia sido desfigurada pelo poder colonial. Os valores da pátria e a noção de pertencimento são exaltados no livro de poemas, levando os angolanos a se organizarem e reagirem. Ambos os textos retratam o processo de independência do país e demarcam o espaço da nação, pois enaltecem de certa forma Angola e reafirmam o sentimento de angolanidade em seus habitantes.

Sobre a importância da reafirmação da identidade presente no texto destinado para o público infantojuvenil, Santos (2006) comenta que apenas africanos 
ou latino-americanos filhos do colonialismo se viram forçados a suscitar a questão identitária, o que, para Fanon (1968), foi uma necessidade:

Nesta situação, a reivindicação do intelectual colonizado não é um luxo mas a exigência de um programa coerente. $O$ intelectual colonizado que situa seu combate no plano da legitimidade, que quer fornecer provas, que aceita desnudarse para melhor exibir a história de seu corpo, está condenado a esse mergulho nas entranhas de seu povo (Fanon, 1968: 175).

A reinvindicação citada por Fanon (1968) é observada na obra de Luandino Vieira a partir da retomada da guerra de independência e as suas implicações: "4. Falou o Grande Kibaia: Nasceu na Luanda. É filho da terra. Portanto não é inimigo. É traidor! Tem de morrer" (Vieira, 2006: 17). O trecho denuncia a assimilação de alguns angolanos pelo sistema colonial português, capaz de fazer com que lutassem contra seu próprio país. O inimigo é visto na obra como o povo invasor, o Outro; já o traidor é aquele que está próximo e comunga dos mesmos valores e da história com os outros habitantes, mas se posiciona contra esse passado em comum. Para uma nação que acabava de se tornar independente, era preciso eliminar a lógica de certa parcela da população que acabou por apoiar o governo colonial na guerra.

Em uma terra subjugada pelo poder colonial, simbolizado no papel dos caçadores de nuvens, a discussão da identidade ganha novos contornos. Dito isso, faz-se necessário retornar à seguinte passagem analisada no capítulo anterior: “5. E respondeu Lengalengenu: Vutuka ku tandu dia muxi ié, Kahima” (Vieira, 2006: 12). O excerto pronunciado pelo português Lengalengenu chama os angolanos de macacos ("kahima") e mostra parte da inferiorização que o processo colonial imprimiu em Angola. Para Fanon (1968), o colonialismo nunca deixou de afirmar que os negros eram selvagens e entendia o continente africano como um local repleto de superstições e fanatismo e que estaria fadado ao desprezo. A fala de Lengalengenu é um reflexo de toda a violência psicológica e simbólica por que passaram os colonizados, o que deixou marcas profundas no debate sobre a identidade angolana, como se pode ver também no romance Mayombe (1980), de Pepetela.

Trazer à luz os aspectos identitários dessa cultura pode ser entendido como uma forma de resistência e luta contra o colonialismo, contra o poder que de- 
clara inferior a cultura do colonizado. A literatura seria um dos espaços cabíveis para a reflexão sobre a identidade dos angolanos, evidenciando o caráter político e de transformação que a palavra escrita carrega e, segundo Mata (2001), é inevitável falar do caráter ideológico e cultural, ao se falar em literatura, sobretudo em África, onde as literaturas nasceram como formas de protesto frente ao conflito entre a cultura portuguesa e a dos africanos.

A nação que acabara de ser repensada necessitava de rever a sua história: "a ausência de um passado conhecido e reconhecido, a míngua de um passado, pode também ser fonte de grandes problemas de mentalidade ou identidades coletivas: é o caso das jovens nações, principalmente das africanas" (Assorodobraj apud Le Goff, 2003: 208). Isso poderia justificar o cariz engajado da literatura para crianças e jovens nos primeiros anos de Angola independente, em que autores como Maria Eugénia Neto e Gabriela Antunes acabaram por criar obras fortemente políticas e nacionalistas. Dois livros se prestam à análise sob essa perspectiva, sendo o primeiro E nas florestas os bichos falaram... (1980), de Eugénia Neto. Narrando a história de uma reunião feita pelos animais da floresta para se discutir sobre de que forma iriam combater a destruição da natureza pelos homens, nota-se uma analogia com a guerra da independência: "Há quantos anos luta o nosso país com armas na mão? Há doze!? Um longo caminho, cheio de lágrimas e sangue! (...) O dia de liberdade para Angola virá e nós também teremos esses parques. Não abandonem o nosso país" (Neto, 1980: 50). Fica claro o tom politizado e combativo do livro, ressaltando o conceito de nacionalidade para crianças e jovens e rediscutindo sua história e a necessidade de se consolidar a ideia de nação, temas importantes para o momento por que passava o país. Durante toda a narrativa, há menções claras aos guerrilheiros e a importância de resistir e lutar por Angola: "Mas vocês sabem, os donos do nosso país querem a sua terra e entram na nossa floresta para se protegerem do inimigo: por isso a eles não devemos atacá-los! Nós devemos antes ajudá-los. Eles são guerrilheiros" (idem: 43). O livro se assemelha mais a um manual didático e pedagógico do movimento libertador angolano e parece pretender inculcar nos jovens leitores a importância da guerra para o futuro da nação.

A segunda obra analisada é $O$ cubo amarelo (1991), de Gabriela Antunes, que aborda o caso da menina Cassova, que, após ficar gravemente doente, ganha um cubo amarelo para se entreter enquanto estivesse acamada, sendo que a terceira face do cubo possui a imagem do ouro: "compreendi que o OURO Ama- 
relo não existia para o bem-estar e a alegria de quem o tirava. (...) E seria bom se o ouro servisse para fazer creches, escolas e hospitais" (Antunes, 1991: 20). O retrato da exploração econômica por que passava Angola é assim efetuado, pois a riqueza advinda do ouro acabava por não beneficiar a população local, mas apenas as empresas estrangeiras que trabalhavam com a extração. A crítica social é enfática, pois a narradora enumera as carências no campo da educação e saúde pública do país, questionando a finalidade do dinheiro conseguido com a extração do ouro. Além da denúncia social, há ainda a exaltação da nacionalidade de um país com a independência recém-proclamada: "Porque o VERMELHO é a cor da Liberdade. (...) E vi um homem dando sangue a uma criança... $E$ vi as cores, ou melhor, O Vermelho da nossa bandeira" (idem: 20). O vermelho remeteria, assim como na obra de Luandino Vieira, ao sangue derramado na guerra de independência, enaltecendo a bandeira angolana, tecida nas cores preta, amarela e vermelha. As duas obras citadas possuem as especificidades nacionais e a guerra de libertação como fio condutor. Pode-se apreender que uma das motivações possíveis para a escolha temática seria a necessidade de se resgatar e preservar a memória cultural vistas de maneira pejorativa pelo colonizador, pois, como ressaltam Macêdo e Chaves (2007), os autores angolanos tomaram para si a tarefa de recontar a história nacional após a independência, comprovada pelo número considerável de textos com temática política ou retomando os caminhos da tradição oral.

A obra de Luandino Vieira quebra o paradigma didático dos livros para crianças e jovens que o antecederam em Angola, pois foi escrita em um período histórico distinto àquele dos escritos de Eugénia Neto e Gabriela Antunes. Como afirma Secco (2007), após 1990, foi inaugurada uma nova forma de escrita na literatura infantojuvenil de Angola e Moçambique e há uma abertura maior para outros temas e construções narrativas. O caráter panfletário foi substituído pela reflexão mais apurada dos eventos passados, o que acontece com $A$ guerra dos fazedores de chuva. Seria preciso que a nação questionasse as suas próprias marcas para que os conceitos de identidade e pertencimento fossem refletidos. O subtítulo do livro de Luandino Vieira, 'guerra para crianças', é revelador porque parece transparecer o intuito do escritor em contar a história para as novas gerações. Mais do que contar o desaire português na colônia, a narrativa engrandece o papel de Angola emergindo na sua independência, não subjugada ou inferiorizada, como tantas vezes se percebeu na fala dos colonizadores. Trazer 
para o primeiro plano a glória angolana na obra faz sentido quando a construção de um sentimento mais amplo de nação, de 'comunidade imaginada' de Anderson (2008), passa a ser considerado, "uma vez que a identidade muda de acordo com a forma como o sujeito é interpelado ou representado, a identificação não é automática, mas pode ser ganhada ou perdida" (Hall, 2003: 21). Dessa forma, percebe-se o intuito de discutir o projeto de nação que a obra possui, contanto a narrativa sob a ótica angolana. Se a história humana é construída por cientistas, biógrafos e também por romancistas e dramaturgos, como considera Francisco Noa (2006), Luandino Vieira, ao contar a guerra para as crianças, demonstra a preocupação em narrar os fatos para quem irá dar continuidade à história do país, para quem é de suma importância compreender a constituição e fortalecimento da nação angolana. O sentimento de enfatizar o papel das crianças como representantes da mudança sempre foi sinalizado por autores angolanos, como Luandino Vieira.

A importância de se avivar o discurso que tentou ser silenciado durante todo o período colonial vai ao encontro do livro de Luandino Vieira, pois a história da guerra de independência é agora contada e construída pelos angolanos: "10. E feriu-se, por muitos dias, grande batalha; e os portugueses foram dizimados; e os seus muenes foram derrotados; Lengalengenu fugiu a cavalo" (Vieira, 2006: 13). A Angola apresentada no livro sai vencedora, assumindo o papel de protagonista no texto. São narrados os acontecimentos da guerra pelo olhar angolano, o que parece fundamental ao se estudar a história do país e de todo o continente africano: "Por exemplo, por história africana entende-se normalmente o discurso histórico sobre África, e não necessariamente um discurso histórico proveniente de África ou produzido por africanos" (Hountondji, 2008: 151). Construir seus próprios dados pode ser entendido como uma forma de refutar a visão reducionista apresentada pelo colonizador, sempre diminuindo a importância do território colonizado.

A fim de recontar a história sob uma ótica angolana, A guerra dos fazedores de chuva utiliza de um verbo forte, "dizimar", ao falar do resultado final da guerra. Segundo Cunha (1986), "dizimar" deriva da palavra "dez" (dízimo) e uma de suas acepções no século XVII era a de matar um soldado em cada grupo de dez, evidenciando a ligação bélica entre a etimologia da palavra com o emprego no livro. A oração não se limita a apenas referir o desaire sofrido pelos portugueses e anunciar a luta libertadora de Angola. Ao descrever o resultado da guerra, 
Luandino Vieira faz uso de três verbos: "dizimar", "derrotar" e "fugir". A utilização do primeiro verbo já seria suficiente para descrever a perda portuguesa na história, mas o autor parece querer enfatizar o fracasso colonial, pois comenta que o exército foi derrotado e o chefe português fugiu. A fuga de Lengalengenu coroa a total derrota portuguesa, pois fugir é comumente considerado um ato de covardia. $O$ chefe do exército de Portugal, ao perceber que não poderá vencer Kibaia Kinene, foge e abandona os seus companheiros de luta, refletindo a falta de lealdade com os seus. $O$ destaque dado à derrota de Lengalengenu pode ser entendido como uma obrigação, no sentido de necessidade, de se escrever a história angolana pelos próprios angolanos, quebrando o silêncio dos subalternos, já desejosos e determinados a recuperar a voz que durante tanto tempo não podia ser ouvida:

A mais grave carência sofrida pelo colonizado é a de estar colocado fora da história e fora da cidade. A colonização Ihe veda toda participação tanto na guerra quanto na paz, toda decisão que contribui para o destino do mundo e para o seu próprio, toda responsabilidade histórica e social. (Memmi, 1977: 86)

A anulação do colonizado tentada pelo colonizador é rechaçada na obra de Luandino Vieira, pois, em sua escrita, há a retomada de decisões e a participação ativa do angolano, de forma a recolocá-lo em seu devido lugar. Partindo do princípio de que nenhuma obra é inocente ideologicamente, $A$ guerra dos fazedores de chuva consegue atuar como a mediadora entre o mundo e o receptor, levando a possibilidade de ampliar a visão crítica do leitor e sua capacidade de construção de seus próprios significados, sem que para isso o texto ganhe um caráter utilitarista. $\mathrm{O}$ autor conseguiria abordar temáticas importantes e densas sem ter de chegar a conclusões mecânicas e óbvias, o que, para Hunt (2010), amplia tanto o pensamento como a capacidade de pensar dos leitores. Caminhando em direção aos níveis mais profundos do texto, Luandino Vieira toca em questões ideológicas sem ser doutrinário, dando ênfase à estrutura na narrativa.

\section{Infâncias marcadas: o olhar da criança sobre a guerra de independência}

O papel que as crianças desempenham em A guerra dos fazedores de chuva 
merece destaque. Ao final da narrativa, após a vitória de Kibaia Kinene sobre o exército de Lengalengenu, os muenes do português são punidos. E os escolhidos para aplicar a punição em Custódio Xavier de Bello Neto são as crianças: "7. E Mbumba iá Kibaia, o Kibaia Kinene, mandou parar. Disse: Só as crianças podem ser ao mesmo tempo vítima, testemunha e carrasco" (Vieira, 2006: 20). O castigo ao traidor poderia ter sido aplicado pelo próprio Kibaia ou por um de seus três muenes, pois os quatro lutaram diretamente com os portugueses. Uma vez que a guerra é para ser contada às crianças, nota-se que os grandes prejudicados e maiores vítimas são elas de fato, que perderam sua infância em função da batalha. Além de vítimas, são testemunhas vivas da morte de seus familiares, assistindo à destruição de seu país. O emprego do termo "testemunha" no excerto parece extrapolar o sentido de atestar a verdade, ser a prova dos fatos; a testemunha, nesse caso, não apenas pode comprovar como viveu e sofreu todas as consequências da guerra, não apenas físicas como ressalta Memmi (1977), como também psicológicas, pois a memória que the foi ensinada na escola não fala de seu povo. A punição final é entregue para as crianças, alterando o significado do gesto. Elas são vítimas, testemunhas e carrascos ao mesmo tempo, assumindo as duas faces da mesma moeda na guerra: foram castigadas e aplicam castigo. $\mathrm{O}$ fato das crianças serem chamadas de carrascos pelo chefe angolano contraria a ideia de fragilidade e ingenuidade muitas vezes atribuída à infância, pois as crianças da obra angolana não se veem representadas por esse modelo infantil e cresceram frente a uma violenta batalha, assistindo à barbárie acontecer em diversos ambientes, como o familiar ou escolar. Outra leitura possível do excerto poderia levar à discussão de que essas crianças angolanas passam a repetir a crueldade que presenciaram e vivenciaram, fazendo com o outro tudo aquilo que sofreram. É a reprodução da violência, aprendida nos gestos do colonizador sobre o colonizado e, muitas vezes, sendo aplicada pelas crianças de maneira mais forte e atroz. As crianças foram chamadas de carrascos não por serem cruéis e desejarem penalizar o traidor, mas porque se viram obrigadas a reagir daquela maneira. Ser carrasco na obra de Luandino Vieira estaria mais próximo a fazer justiça do que punir, numa tentativa de reavaliar e reconsiderar o passado colonial. E como são as crianças as maiores vítimas da guerra, apenas elas poderiam se apropriar novamente da história que lhes foi ocultada ou deturpada, como alerta Fanon (1968). 


\section{Conclusão}

As crianças também indicam um novo tempo na história angolana e possuem "na literatura prometeica, como é a de toda a África, um papel muito importante, de gazuas do futuro, simbolizando, em última instância, o triunfo do novo sobre a velha tradição e sobre a dominação colonial" (Laranjeira, 1995: 128). A nova fase que nasce ao final na obra de Luandino Vieira com a punição aplicada pelas crianças ao traidor angolano encontra na água/rio uma metáfora expressiva: " 11 . O rio Kipakasa morreu; a terra repousou por fim; e viram as crianças que tudo estava bem e recomeçaram a crescer" (Vieira, 2006: 20). A paz no quilombo, alegoria de toda Angola, só é possível, em A guerra dos fazedores de chuva, com a morte do rio, que representa o descanso para a terra já tão fustigada pelos combates e pelos desmandos humanos.

É possível traçar um paralelo entre a morte do Kipakasa com a morte do período colonial, pois este acaba após o final da guerra entre angolanos e portugueses. Ao findar-se, o rio poderia ter levado junto das suas águas uma Angola colonizada, originando uma terra livre da opressão. A nação 'livre' que se ergueu após a guerra precisou passar por um longo e sangrento processo e, a partir dessa renovação advinda da morte do rio, as crianças voltaram a crescer, a vida voltou a ter seu fluxo normal. A passagem acaba por se assemelhar a um rito de passagem, pois apenas quando um morre, o outro pode nascer, discutindo na obra as fronteiras entre ancestral e moderno.

Assim, o livro de Luandino Vieira constrói uma linguagem própria e carregada de simbolismos, criando um campo de tensão entre a natureza, a guerra e a infância, temas tão caros a Angola. Seja através da linguagem que faz uma releitura da tradição oral, dos temas abordados ou do glossário em quimbundo presente ao final do livro, percebe-se que a relação entre os três elementos citados em A guerra dos fazedores de chuva aviva antigas questões cruciais para aquele povo, gerando uma reflexão e ressiginificação do conceito de identidade e nação. 


\section{Referências}

ALVES, Tatiana. Seis estudos sobre Mia Couto. Rio de Janeiro: Celacanto, 2012. ANDERSON, Benedict. Comunidades Imaginadas. São Paulo: Cia das Letras, 2008 ANTUNES, Gabriela. O cubo amarelo, Luanda: União dos Escritores Angolanos, 1991. APPIAH, Anthony. Na casa de meu pai: a África na filosofia da cultura. Rio de Janeiro: Contraponto, 1997.

BACHELARD, Gaston. A psicanálise do fogo. São Paulo: Martins Fontes, 2008. CÉSAIRE, Aimé. Discurso sobre o colonialismo. Lisboa: Sá da Costa, 1978.

CHEVALIER, Jean \& GHEERBRANT, Alain. Dicionário de símbolos. Rio de Janeiro: José Olympio, 2005.

CUNHA, Antônio Geraldo da. Dicionário etimológico Nova Fronteira da língua portuguesa. Rio de Janeiro: Nova Fronteira, 1986.

FONSECA, Maria Nazareth Soares. Literaturas africanas de língua portuguesa: percursos da memória e outros trânsitos. Belo Horizonte: Veredas \& Cenários, 2008.

FANON, Frantz. Os condenados da terra. Rio de Janeiro: Civilização Brasileira, 1968.

HOUNTONDJ, Paulin J. Conhecimento de África, conhecimento de africanos: duas perspectivas sobre os Estudos Africanos. In: Revista Crítica de Ciências Sociais, $n$ o 80 . Coimbra: CES. 2008, p. 149-160.

HUNT, Peter. Crítica, teoria e literatura infantil. São Paulo: Cosac Naify, 2010.

LARANJEIRA, Pires. Literaturas Africanas de Expressão Portuguesa. Lisboa: Universidade Aberta, 1995.

MEMMI, Albert. Retrato do colonizado precedido do retrato do colonizador. Rio de Janeiro: Paz e Terra, 1977.

MATA, Inocência. Literatura angolana: silêncios e falas de uma voz inquieta. Lisboa: Mar Além, 2001.

MACÊDO, Tania e CHAVES, Rita. Literaturas de língua portuguesa: marcos e marcas- Angola. SANTILLI, Maria Aparecida; FLORY, Suely Fadul Villibor (Org.). São Paulo: Arte e Ciência, 2007.

NETO, Agostinho. Sagrada Esperança. Lisboa: Sá da Costa, 1987.

NETO, Maria Eugénia. ... E nas florestas os bichos falaram... Angola: União dos Escritores Angolanos, 1980.

NOA, Francisco. Modos de fazer mundos na actual ficção moçambicana. In: Marcas da diferença: as literaturas africanas de língua portuguesa. CHAVES, Rita; MACÊDO, Tania (Org.). São Paulo: Alameda, 2006, p. 267-274.

SANTOS, Boaventura de Sousa. Pela mãe de Alice: o social e o político na pós-modernidade. São Paulo: Cortez, 2006. 
SECCO, Carmen Lucia Tindó. (Org.). Entre fábulas e alegorias: ensaios sobre literatura infantil de Angola e Moçambique. Rio de Janeiro: Quartet: UFRJ, Centro de Letras e Artes, 2007.

VIEIRA, José Luandino. A guerra dos fazedores de chuva com os caçadores de nuvens. Guerra para crianças. Luanda: Editorial Nzila, 2006. 